\title{
A REGIONAL INVESTIGATION INTO THE RELATION BETWEEN SOIL STRUCTURE, YIELD OF SUGAR BEETS AND NITROGEN SUPPLY ${ }^{1}{ }^{2}$ )
}

\author{
H. KUIPERS \\ Agricultural Experiment Station and Institute for Soil Research, \\ T.N.O., Groningen
}

\section{SUMMARY}

The relation between soil structure (visually determined), nitrogen dressing and yield of sugar beets was studied in 1952 in north-western Groningen, by means of a series of 50 experimental fields with 10 different amounts of nitrogen fertilizer, applied on each field.

By introducing the difference between highest and lowest yield on a field as a growth factor, representing the response to nitrogen treatment, the influence of soil structure was found to be the same in the case of both low and high nitrogen dressings. There proved to be a relation between soil structure and nitrogen response, in that bad structures were associated with a great response to nitrogen, in such a way, that the yields without nitrogen were remarkably low. Probably this explains why, in this investigation, higher optimum amounts of nitrogen were found in the case of bad structures than in that of favourable structures. However, differences in soil structure accounted for only a small part of the wide variation in nitrogen response (from 4.2 up to more than 23.5 metric tons/ha) in the old arable fields investigated, which received no organic manure.

In addition to these influences, i.e. soil structure and nitrogen dressing, the factors $\mathrm{pH}$ and sowing date proved to play a part (Figs. 7 and 8).

By means of structure mapping the mean influence of soil structure on the yield of sugar beets in farming practice was estimated at $2.4 \%$ in this investigation.

The results of structure determinations in the laboratory indicate that the structure of the marine clay soils studied can probably best be characterized by the amount of large pores.

\section{OBJECT}

This investigation was carried out as an E.C.A. project ${ }^{3}$ ) in the Marne district of north-western Groningen, bordering the Waddenzee (Fig. 1).

In order to obtain some information about the relation between crop yield, soil structure and nitrogen supply, sugar beets (Klein Wanzleben) were grown in 1952 on a series of 50 experimental fields, each consisting of 12 plots on which 10 different nitrogen dressings, ranging from 0 to $200 \mathrm{~kg} \mathrm{~N} /$ ha were applied. The plots without nitrogen and those with the highest amounts were duplicated in each field.

The marine soils in this district chiefly belong to three groups :

1 the calcareous, young marine soils, widely divergent in clay content in the polders along the Waddenzee and the Reitdiep;

2 the non-calcareous, older, unstable, sandy loam soils in the central part of the district;

3 the non-calcareous, sticky clay soils in the south-eastern part, near Zuurdijk.

1) Received for publication May 11, 1955.

2) A detailed report on this investigation will be published in "Verslagen van Landbouwkundige Onderzoekingen".

3) The project could be realized thanks to a grant from the funds of the Economic Cooperation Administration (later Mutual Security Administration). 


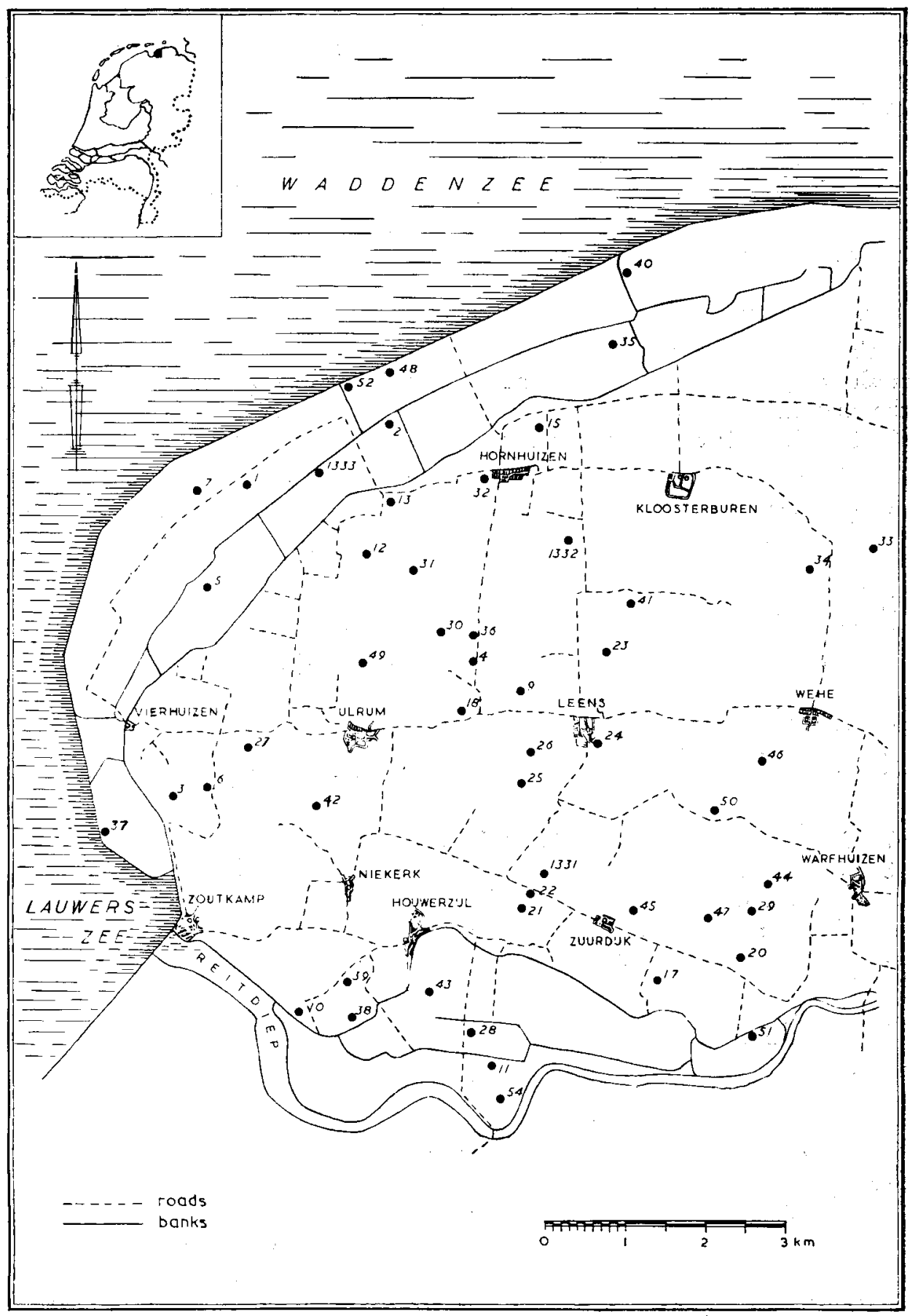

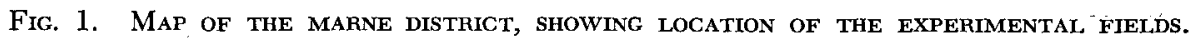


The experimental fields were distributed in such a way that, according to structure mapping carried out in the autumn of 1951, a wide variation in soil structure could be expected. $\mathrm{P}$ and $\mathrm{K}$ dressings were the same for all fields, viz. $100 \mathrm{~kg} \mathrm{P}_{2} \mathrm{O}_{5} / \mathrm{ha}$ and $200 \mathrm{~kg} \mathrm{~K} \mathrm{~K}_{2} \mathrm{O} / \mathrm{ha}$. Fields carrying clover or receiving organic manure in 1951 were not included, nor were fields which were covered with grass at any time. Ground water levels were generally rather deep (below $1 \mathrm{~m}$ in May), and all the profiles except one showed decreasing clay contents in proportion to increasing depths.

In addition to chemical soil tests, several methods for determining soil structure were applied on each experimental field. Ground water levels were measured regularly.

\section{AdjustMent OF THE ResUlts OF MEASUREMENTS}

The relation between the amount of nitrogen and the yield, expressed as fresh weight of roots, was determined graphically in respect of each field. In the analysis of the influence of the growth factors the highest and lowest yield obtained by this adjustment were used as yield indexes for each field.

The following growth factors were taken into account:

1 The difference between highest and lowest yield. This factor serves as a check, and is a substitute for the factor nitrogen mineralization in the soil (see 8).

2 Sowing date.

3 Visually determined soil structure in spring. In the present investigation this index was evaluated at between $4-$ and $7+$. It is determined in the field by a specialist.

4 Visually determined soil structure in the autumn.

$5 \mathrm{pH}-\mathrm{KCl}: \mathrm{pH}$ measured in $1 \mathrm{n} \mathrm{KCl}$ solution.

6 lrb index, the logarithm of the relative amount of bases present in the soil (VISSER, 1942).

7 Percentage of particles $<16$ microns.

8 Nitrogen mineralization in the soil (HARMSEN et al., 1949).

9 P-citr. P content, $\mathrm{P}$ soluble in $1 \%$ citric acid.

$10 \mathrm{~K}-\mathrm{HCl}$ : $\mathrm{K}$ content, $\mathrm{K}$ soluble in $0.1 \mathrm{n} \mathrm{HCl}$.

11 Content of organic matter.

12 Relative ground water fluctuation index (VISSER, 1950).

13 Difference in mechanical resistance between the layers $0-15$ and $15-30 \mathrm{~cm}$ below the surface. This value was determined in spring and autumn by means of a simple penetrometer. Later on, the two sets of observations were combined.

Only 46 out of the 50 experimental fields could be taken into account in yield analysis, as one of them quite failed by a mistake in the treatment; a second was flooded for a long time and the crop in it could be harvested only after being frozen; a third was badly damaged by diseases; and a fourth gave doubtful results.

The factors which would probably account for the differences in yield between the various experimental fields were found by means of two polyfactor analyses (FERRARr, 1952a). In the case of the highest yields these factors were : 1. visually determined soil strucure, $2 . \mathrm{pH}-\mathrm{KCl}, 3$. sowing date. In the 
case of the lowest yields the same factors were found and, in addition, the difference between highest and lowest yield ( $\mathrm{N}$ response) also appeared to play a part.

From the mathematical verification (FERRARI, 1952b) it appeared that the correlations between these factors had not been fully taken into account. The correlations are shown in Table 1.

Table 1.

\begin{tabular}{l|c|c|c}
\hline $\begin{array}{c}\text { Table of } \\
\text { correlations }\end{array}$ & $\begin{array}{c}\text { Sowing } \\
\text { date }\end{array}$ & $\mathrm{pH}-\mathrm{KCl}$ & $\begin{array}{c}\text { Structure index, } \\
\text { autumn }\end{array}$ \\
\hline $\begin{array}{l}\text { N response } \ldots \ldots \\
\text { Sowing date } \ldots \ldots .\end{array}$ & -0.01 & -0.07 & -0.42 \\
$\mathrm{pH}-\mathrm{KCl} \ldots \ldots \ldots$ & -0.15 & -0.30 \\
& & +0.47 \\
\hline $\begin{array}{l}1 \% \text { level } \mathrm{r}=0.36 \\
5 \% \text { level } \mathrm{r}=0.28\end{array}$
\end{tabular}

The results were readjusted according to a numerical graphical method which will soon be published by Ferrari and Sluysmans in Plant and Soil. The mathematical verification was the same as that used in the polyfactor analysis. The results of this check are shown in Table 2 . Here, $\bar{a}_{i}$ is a most probable scalar for the yield axis if the algebraic form of the curves is assumed to be correct. $S \bar{a}_{i}$ is the standard deviation of $\bar{a}_{i}$ and $t$ is the quotient of $\bar{a}_{i}$ or

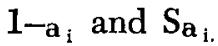

Table 2.

Verification of the numerical graphical method -46 experimental fields

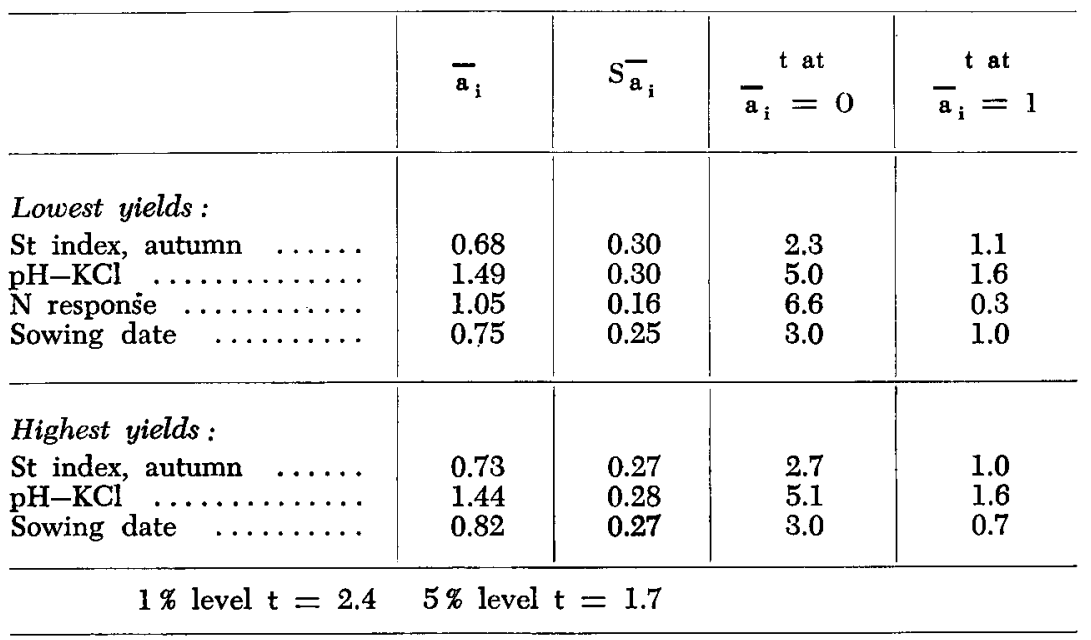

If $\bar{a}_{i}$ does not differ significantly from zero, the influence of the factor is not significant. If the value differs significantly from 1 , it is statistically significantly proved that the curve obtained is not the same as the one that would be found by numerical adjustment on the assumption that the algebraic form of the curves is correct. The $t$ values calculated show that all influences are 
significant and that the curves nowhere appear to be not in accordance with a numerical adjustment.

Fig. 2 shows a graph in which the lowest yield y of each field is plotted against $f(x)$, i.e., the yield that would be expected according to the growth factors (FERRARI, 1952c).

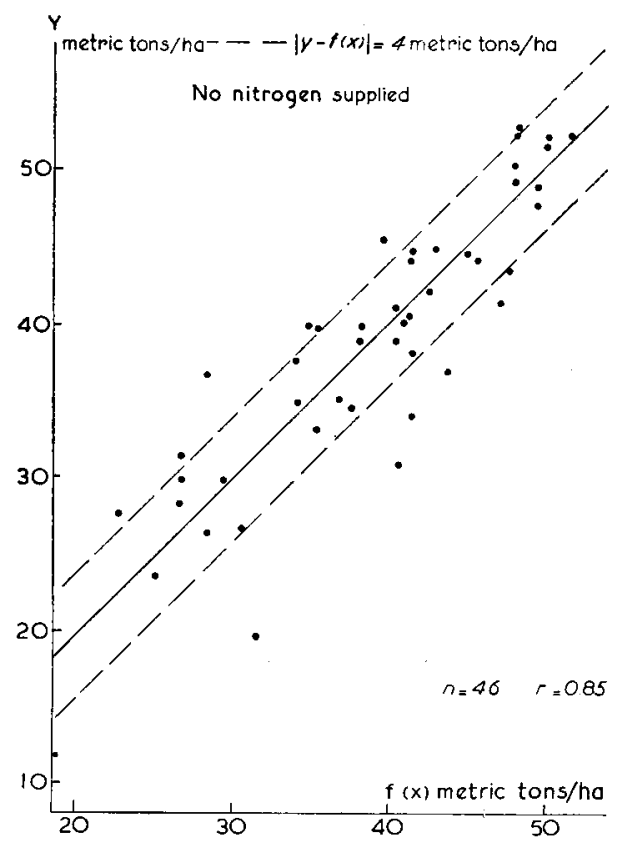

Fig. 2. Yield EXPECted aCcondng to growth FaCtors investigated ( $\mathrm{f}(\mathrm{x})$ ), versus YIELD MEASURED IN THE FIELD (y). NO NITROGEN SUPPLIED.

This graph illustrates the agreement of the yield figures, as computed from the influences of the growth factors, with the yield figures found by measurement in the field, when no nitrogen was added.

\section{Results}

In Fig. 3 a summary of all nitrogen amount yield curves is shown.

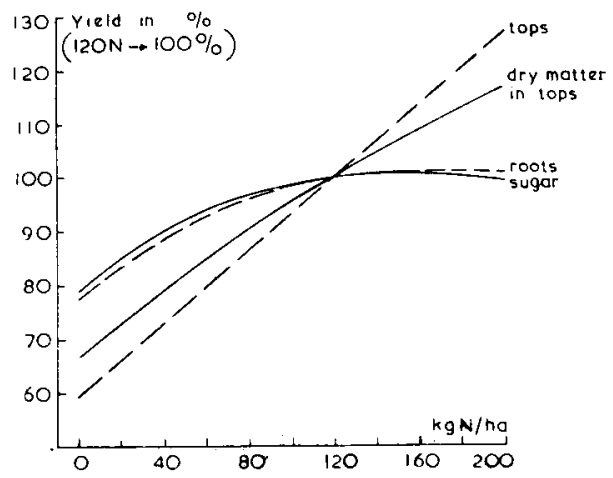

Fig. 3. Influence of Nitrogen dREssing on yoeld of RoOTs, SUgar, tops and amount OF DRY MATTER IN TOPS. 
All the values are assumed to be $100 \%$ in the case of a quantity of $120 \mathrm{~kg}$ $\mathrm{N} / \mathrm{ha}$, which is a normal dressing in farming practice. The absolute values at this level are : 1) yield of roots : 49.3 metric tons/ha; 2) tops : 46.1 metric tons $/$ ha ; 3) yield of sugar : 8.58 metric tons/ha ; 4) yield of dry matter in the tops : 7.30 metric tons/ha.

The relatively small amounts of dry matter in the tops, and of sugar, in the case of high nitrogen dressings, can be explained by relating the percentages of sugar in the roots and dry matter in the tops to the nitrogen dressing. This is shown in Fig. 4 by the decrease in the two contents with increasing amounts of nitrogen.

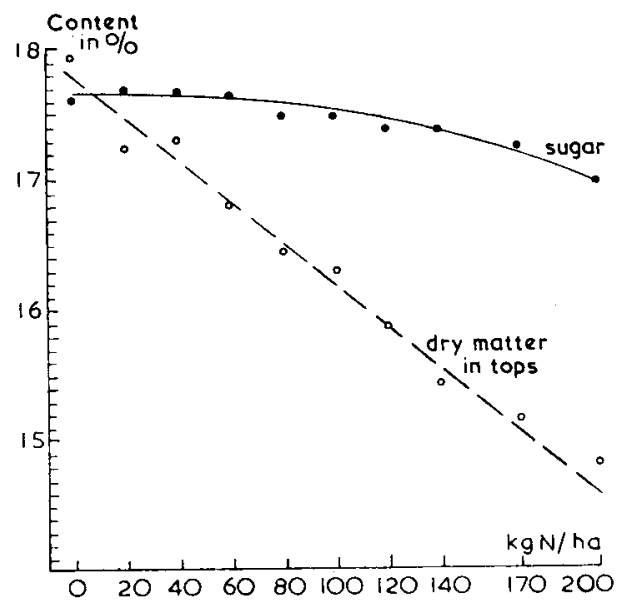

Fig. 4. SUGAR CONTENT OF BEETS AND DRY MATTER CONTENT OF TOPS IN RELATION TO NITROGEN DRESSING.

In Fig. 5 the curves for nitrogen dressings versus yield of roots are divided into two groups, viz. for 31 experimental fields with a structure index $>5$, and for 18 fields with an index $<5$.

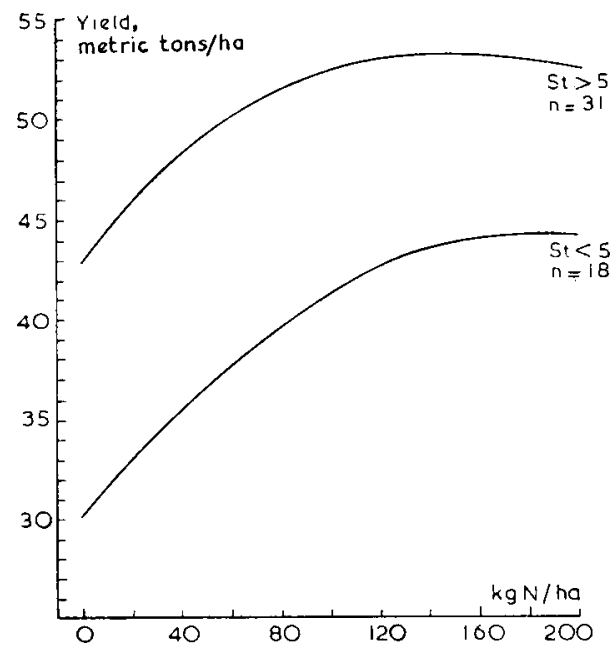

Fig. 5. YIELDS FROM FIELIDS CLASSIFIED IN TWO GROUPS ACCORDING TO STRUCTURE INDEX, IN RELATION TO NITROGEN DRESSINGS.

The curves show distinct differences in level and optimum nitrogen dressing. In the case of unfavourable structures optimum nitrogen dressings are higher by 30 to $40 \mathrm{~kg} / \mathrm{ha}$; and the influence of soil structure seems to make a dif- 
ference of 13 metric tons/ha without nitrogen and about 9 metric tons/ha in the case of an optimum addition.

As the two groups are not likely to differ from each other in St index only, these differences should not be attributed only to this factor.

As regards results from the numerical graphical method, it can be said a priori that there should be no difference between the curves relating a certain growth factor to the lowest and the highest yields, as otherwise the conclusion could be drawn that this influence of the growth factor on yield would change if the amount of nitrogen supplied was varied. So this change would be explained by the nitrogen factor, which, in this investigation, is characterized by introducing the difference between highest and lowest yield on each experimental field as a growth factor.

The analysis of the highest and the lowest yield was made by two different persons separately. The results for the factors soil structure, $\mathrm{pH}-\mathrm{KCl}$ and sowing date are shown in Figs. 6, 7 and 8.

Fig. 6. INFLUence of visualiy DEterMINED SOIL STRUCTURE ON LOSS OF YIELD.
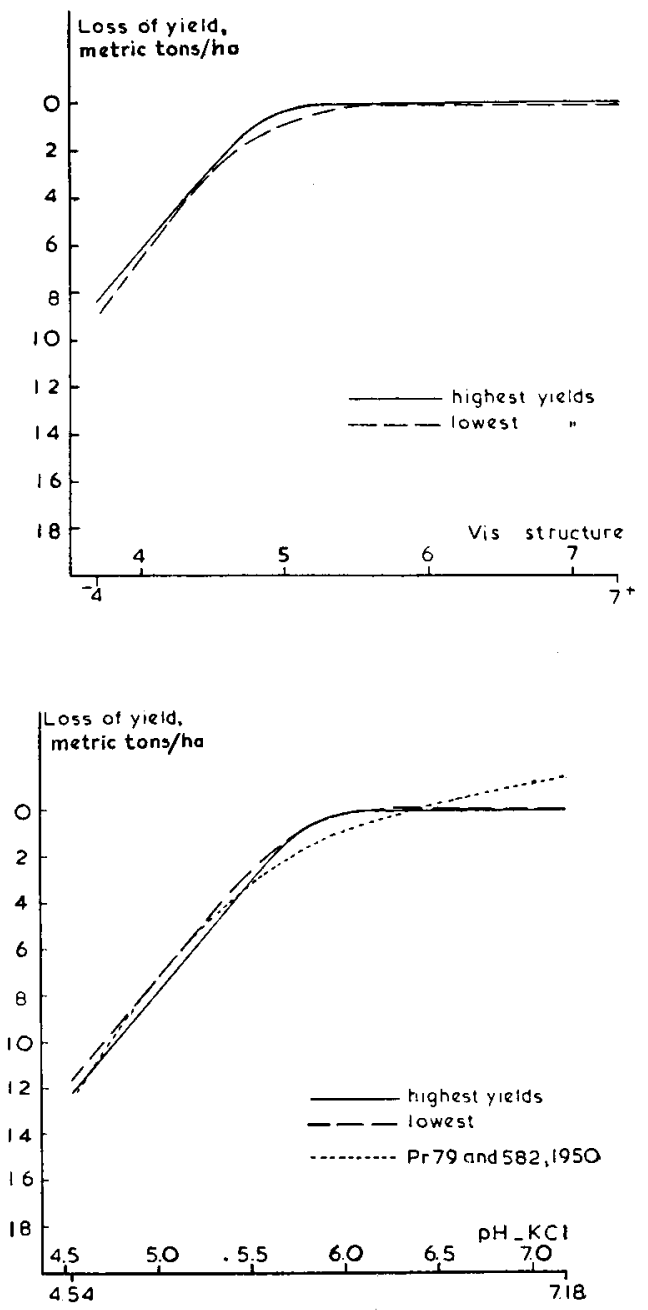


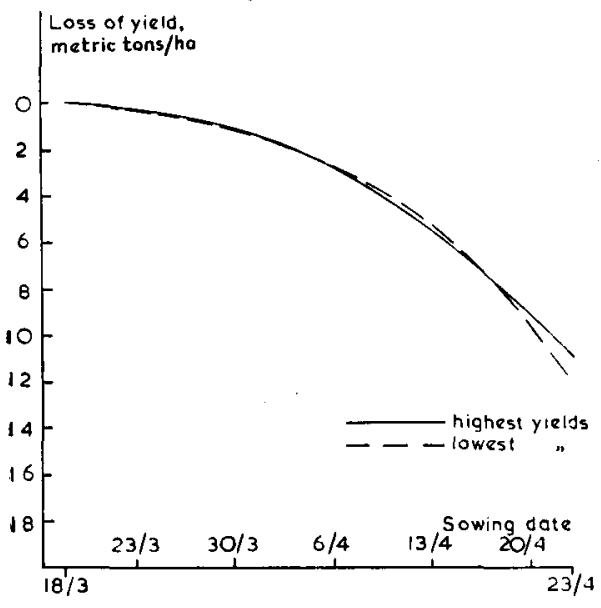

Fig. 8. Influence of sowing Date on LOSS OF YIELD.

The number of metric tons/ha by which the yield remained below the yield at the most favourable value of the growth factor, is plotted in a negative direction on the $y$ axis. It appears that there is indeed a close resemblance between the curves for the highest and lowest yields.

The curves for the sowing date are not quite satisfactory. As the optimum condition (sowing date March 18) was found only on three of the normal experimental fields, and the next sowing lasted till April 5, the highest part of the curve is rather uncertain. Besides the normal fields there were three sowing-date experimental fields. On one of them the first sowing could be carried out on March 20, but bad weather made it necessary to stop sowing until April 4. According to results from these three fields, the influence of sowing date on yield of roots is less than that found after yield analysis.

The $\mathrm{pH}$ curves are normal, as is shown by the dotted line in Fig. 7, which represents the results from two experimental fields laid out to study the influence of liming on a clay soil (Dollard clay) in north-eastern Groningen, carrying sugar beets, in 1950 (CASTENMILLER, 1952).

It was found that the difference between the highest and lowest yield, i.e. the yield increase owing to nitrogen treatment, showed a relation to the lowest yield, but not to the highest. The relation to the lowest yield was rectilinear. This implies that the inclination of the line must be $45^{\circ}$, according to the following reasoning. If, in a graph, the difference between highest and lowest yield $\left(\mathrm{y}_{\mathrm{d} \text {.ff }}\right)$ is plotted on the horizontal axis, and the highest yields $\left(\mathrm{y}_{\max .}\right)$ and lowest yields $\left(\mathrm{y}_{\mathrm{min}}\right)$ are presented on the vertical axis, a horizontal line will be found for the highest yields, as they were not influenced by nitrogen response, and the straight line mentioned above will be found for the lowest yields. This is expressed by :

$\mathrm{y}_{\max .}=\mathrm{a}$ and $\mathrm{y}_{\min }=\mathrm{m}_{\mathrm{g}} \mathrm{y}_{\mathrm{diff}}+\mathrm{b}$, in which $\mathrm{a}, \mathrm{b}$ and $\mathrm{m}$ are constants. From this it follows that:

$y_{\max }-y_{\min }=y_{\text {diff. }}=a-b-$ m. $y_{\text {diff }}$

So $m=-1$, or the line for the lowest yields will have an inclination of $45^{\circ}$.

In Fig. 9 the line obtained by yield analysis is shown. 
Fig. 9. Influence OF NITROGEN RESPONSE ON LOSS OF YIELD; NO NITROGEN SUPPLIED.

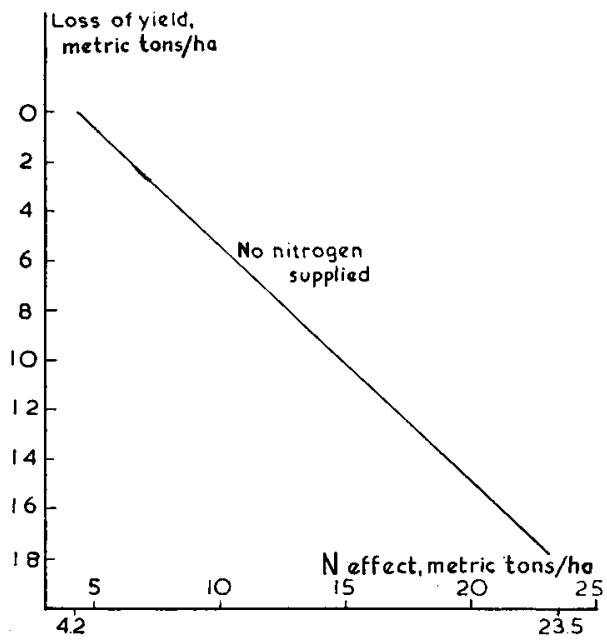

The vertical range is about 18 metric tons/ha and the horizontal one about 19 metric tons/ha. So this line is in conformity with what was to be expected. The wide range of reactions to nitrogen treatment on these old arable fields, to which no organic manure had been supplied, should be well noted.

If, in order to compare Fig. 6 with Fig. 5, the fields are again divided into the two groups with structure indexes smaller and greater than 5 , we find from Fig. 6 that there is a difference in yield of about 6 metric tons/ha between these groups. This is not in conformity with Fig. 5, the reason being that the two groups in Fig. 5 do not differ only in soil structure. To illustrate this, Fig. 10 shows all the correlations between the factors investigated which are significant at the $5 \%$ level.

The circles indicate the factors. Correlations significant at the $1 \%$ level are shown as pairs of unbroken lines, the length of which is proportionate to 1-r, and the distance between them to $r$ itself, $r$ being the correlation coefficient. The coefficients significant at the $5 \%$ level, but not at the $1 \%$ level, are indicated by small dotted strips.

From this illustration it is clear that a group of fields with low structure indexes will differ from a group with high indexes, not only in structure index, but also in $\mathrm{pH}$ and in response to nitrogen treatment. The difference in response to nitrogen can be seen from Fig. 5 , as the lowest yields differ by about 13 metric tons/ha in the case of the two structure groups, and the highest yields by about 9 metric tons/ha. The response to nitrogen is therefore about 4 metric tons/ha greater in the case of a bad structure than in that of a good structure. The total differences in response to a nitrogen fertilizer between all the fields are much greater, as can be seen from the extreme values, viz. 4.2 and 23.5 metric tons/ha. Consequently, the differences in response to nitrogen can be explained only to a small extent by soil structure.

The fact that the difference between experimental fields with structure indexes smaller and greater than 5 according to Fig. 6 is even less than 9 metric tons/ha (shown in Fig. 5 in the case of highest yields) can be explained by the correlation between $\mathrm{pH}$ and structure index.

As regards the relation between the response to nitrogen and soil structure, I 78 


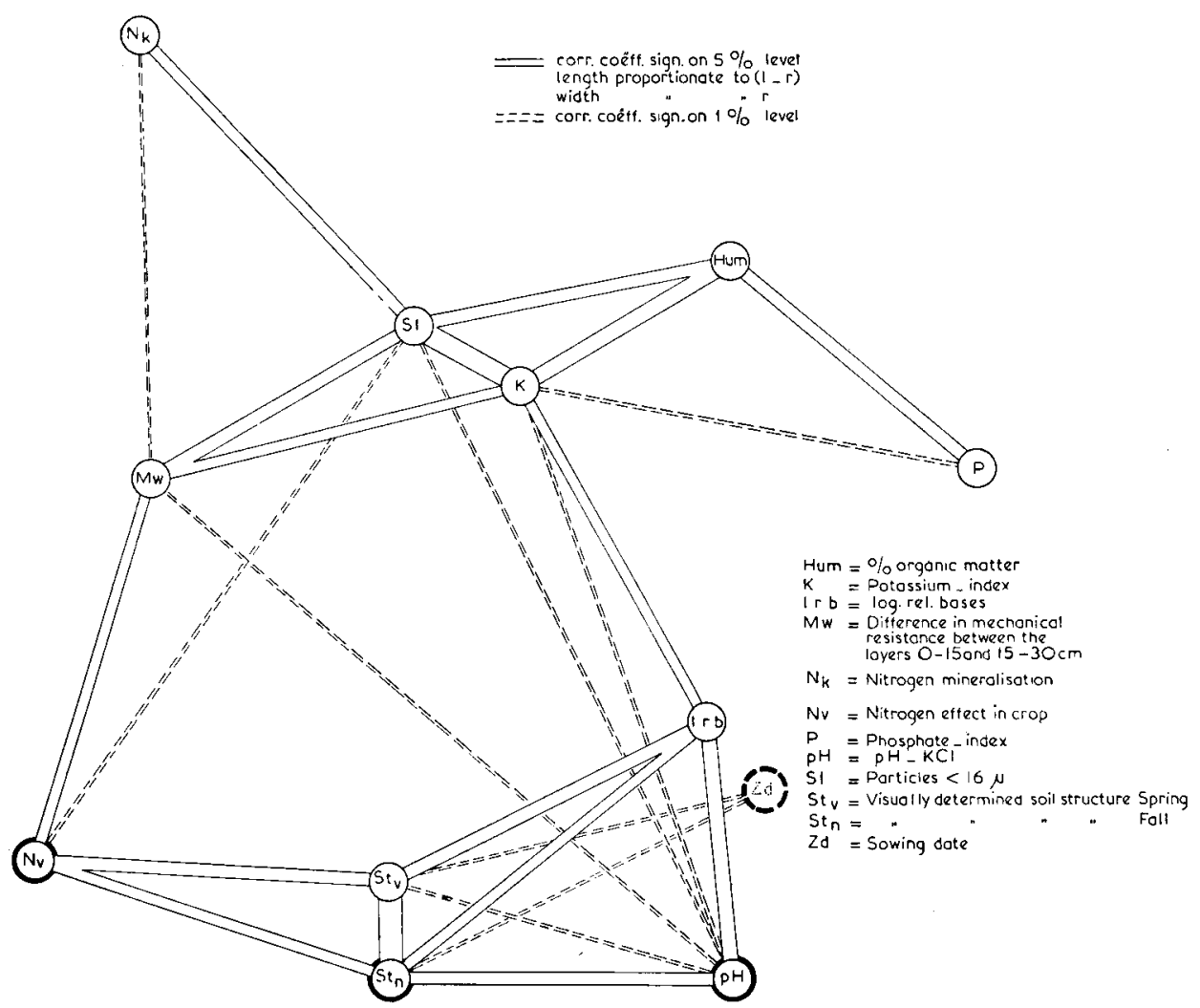

Fig. 10. Diagram of the CORRELAtions Between the various factors.

it has been stated that the optimum nitrogen dressing was higher in the case of soils with poor structures. As the factor "difference between highest and lowest yield" was significantly correlated with the structure index and not with the $\mathrm{pH}$, it is reasonable to attribute this phenomenon to soil structure. Although, strictly speaking, this has not been proved, no more calculations were made, as the determination of the optimum nitrogen dressing for each individual field was not accurate enough.

Summarizing, the relation found between the soil structure, nitrogen dressing and yield can be described as follows : the influence of soil structure on yield was the same with high and low nitrogen dressings, but in the case of low dressings it appeared that bad structures were accompanied by defects in the nitrogen supply, owing to which the yields in the case of low nitrogen dressings were exceptionally low. The fact that this phenomenon did not occur in the case of higher nitrogen dressings, although the optimum dressing was higher at low structure indexes, prompted the conclusion that these exceptionally low yields were caused by defects in the nitrogen supply.

Fig. 10 shows that the differences in yield cannot be explained as satisfactorily from other measured factors - a fact which could be due to correlations between the different factors. The factors form two groups. All the factors of 
the group in the lower part of Fig. 10 are used, as the structure index in spring relates to the same factor as the structure index in autumn. This also applies to $\mathrm{pH}-\mathrm{KCl}$ and the lrb index.

A great advantage of the visually determined structure index is the low correlation with clay content. The results of aggregate analyses (not shown)

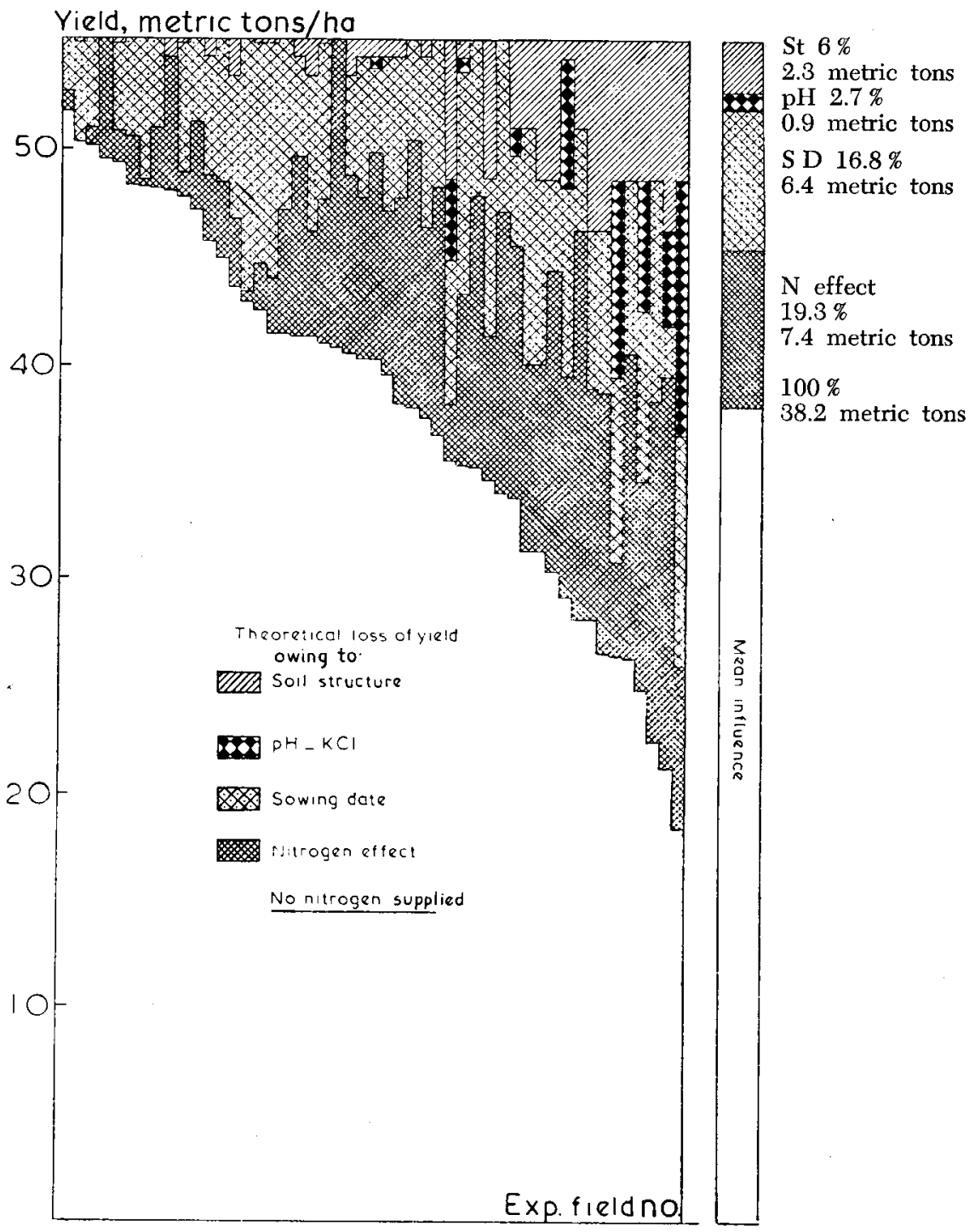

Fig. 11. INFLUENCE OF THE DIFFERENT GROWTH FACtors IN THE CASE OF EACH INDIVIdUAL EXPEHIMENTAL FIELD.

do exhibit a clear correlation with clay content. As the structure index was correlated with the air content of the soil at the moment of sampling, and furthermore, the most important factor in determining the visual index appeared to be the porosity of the soil, it is probable that the amount of large pores will afford the best possibilities for characterizing the soil structure on the 180 
soils investigated. The relation of this factor to the more fundamental growth factors, such as heat exchange and air diffusion, has recently been discussed by D. A. DE VRies (1953).

The INFLUENCE OF SOIL STRUCTURE ON TOTAL PRoDUCtion

Fig. 11 shows the influence of the different factors on the lowest yields in the case of each individual experimental field.

The top line of the diagram shows that, in theory, a yield of 56.2 metric tons/ha was to be expected from each field without application of nitrogen dressings, when the four factors discussed had optimum values. Different types of shading show what proportion of this yield was not obtained, as a result of the failure of each of the individual factors to reach optimum value. These calculated yields of plots without nitrogen dressing are plotted along the horizontal axis of Fig. 2. The mean influence of each factor is shown at the side of Fig. 11. As the yield from early sowing dates was rather uncertain, it is possible that this influence has been overestimated. The influence of the other factors will also be overestimated if they are applied to the whole region investigated, as the nitrogen response on the fields which did receive organic manure, and which were not investigated, will probably be low. Moreover, fields with extreme structures were preferred.

In the case of soil structure, however, it is possible to make a very rough estimate of the influence on total production, as visual structure determinations were carried out in the autumn of 1951 on more than 1,000 fields (20-25\%) throughout the whole region of 7,000 to $8,000 \mathrm{ha}$, and on 23 of these fields experimental fields were laid out in 1952. By means of results from these 23 fields a relation between the structure indexes in the autumns of 1951 and 1952 was calculated, and from this it appeared that the influence of soil structure visually determined, accounted for $2.4 \%$ of the yield in the case of $120 \mathrm{~kg}$ of nitrogen/ha if only sugar beets had been grown in the region, which means the production from $150-200$ ha of the soils in this area.

\section{LITERATURE CITED}

Castenmiller, G. M.: De bekalkingsproefvelden Pr 79 en 582. Verslag Proefboerderi Nieuw-Beerta, 1946-1950 (1952) 55.

Ferrari, Tн. J.: Een onderzoek over de stroomruggronden van de Bommelerwaard met als proefgewas de aardappel. Versl. Landbouwk. Onderz. No. 58.1. (1952). a. 17-29; b. $107-110$; c. 113.

HARMSEN, G. W. and D. J. LiNdenbergh : Investigations on the nitrogen nutrition of plants I. A new method for the determination of nitrogen requirement of soils. Plant and Soil, 2 (1949) 1-29.

Visser, W. C. : De kenschetsing van de kalktoestand door een combinatiecijfer : de lrbwaarde. Versl. Landbouwk. Onderz. 48 (1) A (1942) 1-29.

- - : Agrohydrologische studies betreffende geestgrond. Versl. Landbouwk. Onderz. 56.9 (1950) 52-54.

VRIES, D. A. DE : Natuurkundige beschouwingen omtrent de diffusieweerstand en het warmtegeleidingsvermogen van gronden. Landbouwk. Tijdschrift 65 (1953) 676-683. 